\title{
Discussion on the Management of Graduate Teaching Secretary
}

\author{
Tingting Wu and Juan Wang*
}

College of Cyberspace Security Chengdu University of information technology Chengdu, Sichuan, 610225

*Corresponding author. Email: wangjuan@cuit.edu.cn

\begin{abstract}
As the top of the national education system, graduate education is the main way to cultivate high-level professionals and an important pillar of national talent competition. In recent years, the enrollment of graduate students has been continuously expanded, and the enrollment has exceeded 3 million by 2020 . On the one hand, it shows that the rapid development of graduate education in China, on the other hand, it also leads to some problems in graduate management. This paper discusses the problems and improvement measures of graduate student management from the perspective of teaching secretary in the front line of teaching management.
\end{abstract}

Keywords: Graduate students, Teaching secretaries, Teaching management, Solving difficulties.

\section{THE JOB CONTENT OF GRADUATE TEACHING SECRETARY}

Graduate education is generally in the charge of the Graduate Department of the University. There are training office, degree office, Enrollment Office, discipline construction office and other institutions, which are specifically aimed at the cultivation and management of graduate students (see Figure 1). However, the teaching secretary of independent college has to face all the tasks set up by the Graduate Office.

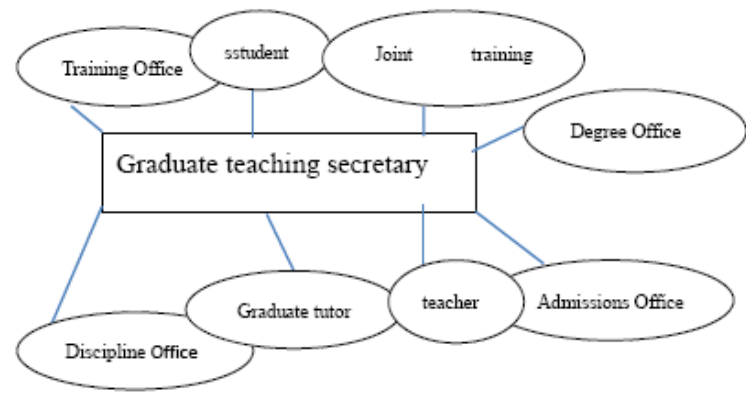

Figure 1 The structure of the service object involved in the work of the graduate teaching secretary.

\subsection{Daily Teaching Management of Graduate Students}

Assist the leaders in charge of daily teaching management, formulate and implement the postgraduate training program. According to the documents of the graduate department, the teaching tasks and lesson plans are issued and reported every semester, and all kinds of problems encountered in teaching management are coordinated and solved. A series of tasks, such as graduate teaching assistant, mid-term examination, teacher transfer and suspension, collection of teaching reform project acceptance materials, professional practice assessment and so on, are about to end the class. Teachers are reminded to set test questions and arrange examination time. After the examination, the teacher should hand in the report card and file the test paper.

\subsection{Management of Graduate Degree Work}

Assist the leaders in charge to arrange the thesis opening, mid-term assessment and defense of postgraduates, assist the degree evaluation sub committee to do a good job in the examination of graduation qualification, the two-way selection of teachers and students' tutors, the review of excellent dissertation data, and the guidance of filling in, statistics, filing and other work related to the reply of graduates. These seemingly simple but complex work must be carried out in strict accordance with the teaching plan. A little negligence will cause teaching accidents, which will affect students' learning at a small level, and affect their career and development in a large way. 


\subsection{Management of Postgraduate Enrolment}

Enrollment work should be the most important work in all graduate teaching work, including the formulation of enrollment brochures and enrollment professional catalog, the determination of enrollment number and bibliography, re-examination, adjustment and so on. It takes nearly a year from the beginning of the enrollment plan to the end of the enrollment work, which requires a lot of energy. There are many links and risks, and no mistakes can be tolerated. Due to the situation of epidemic prevention and control this year, the re-examination of postgraduate students in our university adopts the way of network remote interview, which is the first time in history, and everyone dare not slack off. After more than two months of training and a drill, 98 students through the network remote retest, the final admission of 72, successfully completed the enrollment task.

\subsection{Management of Postgraduate Discipline Construction}

In order to strengthen the deep integration of industry, University, research and application, and better serve the development of national related industries, the status of discipline construction fundamentally reflects and reflects the level, characteristics and academic status of a university. This is an unconventional work, such as various application work related to subject evaluation, degree program or discipline construction, during which a large amount of materials need to be collected.The teaching secretaries need to participate in the whole process and do a lot of work in each link.

\section{DIFFICULTIES FACED BY GRADUATE TEACHING MANAGEMENT}

\subsection{The Scale of Graduate Enrollment has been Expanded}

With the increase of the number of graduate students, it brings new pressure and challenges to the management of graduate education in Colleges and universities in China. The number of graduate students is increasing, but the number of graduate education management staff has not changed, resulting in the graduate teaching secretary has been unable to meet the requirements of the current education management work, thus greatly affecting the quality of graduate education management.

\subsection{The Structure of Graduate Students is Complex}

With the expansion of the source of graduate students, the types of postgraduate training are also increasing, including not only graduates who should be past graduates, but also directional and non-directional students, students majoring in this field and interdisciplinary students. Postgraduates have great differences in social experience, life style and age. The complexity of the group leads to the difficulty of graduate education management.

\subsection{Not Paying Enough Attention to Graduate Teaching Secretary}

In recent years, with the expansion of the scale of graduate students and the downward shift of graduate management, the work of graduate teaching secretary in secondary colleges is becoming more and more arduous, but its status, role and hard work are difficult to be recognized. There are some unreasonable aspects in the distribution of interests and the evaluation of professional titles. Graduate teaching secretarial work is a comprehensive service work, usually many people think that this is not an important teaching role, that is, just arranging courses according to grades, and that individuals are competent. Based on this idea, many graduate teaching secretaries also have several positions. In addition to managing graduate teaching affairs, they also serve as research secretaries, taking into account discipline competitions, training and college office work. It is often that multiple departments issue various notification tasks at the same time, and many affairs need to be completed at the same time, and all kinds of materials are piled up like mountains. All the work pressure on one person, but also to endure the constant urging of the superior department, the pressure can be imagined.

Teachers' incomprehension also increases the pressure of graduate teaching secretaries. For example, in arranging classes, each teacher has his own requirements. Some of them are arranged according to the limited driving date of private cars, and some are arranged according to the time for taking care of the children and the elderly. This will inevitably increase the work content and intensity of the secretary. Another example is the need for students to submit materials on time. There are always some students who can not submit materials on time due to various excuses, some students can not come back from internship, and some tutors cannot sign outside. Another example is the arrangement of the members of the various defense links, and there are always teachers who have opinions, so it is difficult to carry out the work for a time. The tedious work made them unable to innovate in their working methods, and their enthusiasm for work gradually faded. 


\subsection{The Graduate Teaching Management Team has Strong Mobility}

Because this group is not paid attention to, their career prospects are not optimistic for a long time. There are few incentive mechanisms for graduate teaching secretary posts in Colleges and universities. It is difficult to have specific measurement indicators for the work. The post pay is generally low, and the promotion opportunities are not very good. Energy input is not proportional to the harvest, which makes them lack of enthusiasm for work. There are few opportunities to get systematic learning and professional training in their daily work. They can only rely on accumulated experience to complete their work. When they encounter new problems, they can only explore them slowly. Therefore, many graduate secretaries will choose other positions or seek another way out when they rotate their posts, which leads to the instability of graduate teaching management team. The frequent flow of personnel often leads to the teaching secretaries of each session being familiar with the new workflow, which is not conducive to the smooth development of graduate teaching. If there is no stable teaching secretary team, it is not conducive to the long-term development of colleges and universities.

\section{HOW TO SOLVE THE PROBLEMS FACED BY GRADUATE TEACHING SECRETARY}

From the above work content and characteristics of teaching secretary, we can see that it is not easy to be a qualified and excellent teaching secretary. Combined with my practical work experience, in order to improve the management level of graduate students, we should focus on the following aspects:

\subsection{Provide Job Skills Training Opportunities}

Graduate teaching secretary is not only a manager, but also a service provider. Many times, they need to answer the questions of teachers and students at any time. An excellent teaching secretary should not only be familiar with the teaching management system, but also learn some knowledge of management, education and public relations, and more importantly, be familiar with the relevant professional knowledge system. It is suggested to strengthen the multi-channel system training for the graduate teaching secretary group, strengthen the computer level of the graduate teaching secretary, implement information-based teaching management, enhance the file management ability, effectively save all kinds of electronic files of teachers and students and update the information in time, so as to ensure the authenticity and integrity of the information of teachers and students, so as to improve the quality and efficiency of work. The combination of theoretical knowledge and teaching management practice can better serve teachers and students.

\subsection{Establish and Perfect the System of Human Body for Teaching Secretary of Graduate Students}

Because the current teaching secretaries of graduate students in Colleges and universities are full of several posts, colleges and universities should realize the importance of graduate teaching work, and be able to specially engage in the management of graduate teaching, establish a sound system of using graduate teaching secretaries to ensure the stability of the teaching secretary team.

\subsection{Enhance Professional Identity}

First of all, graduate teaching secretary is an indispensable part of graduate teaching in Colleges and universities. If the graduate teaching secretary is not on the post, many teaching work will not be implemented, teaching order is chaotic, and even teaching accidents occur. Secondly, we should attach importance to the work of graduate teaching secretary, understand the practical difficulties in their work and actively help solve them, so as to form a good working atmosphere. Finally, teachers and students should respect the graduate teaching secretary, earnestly implement the work arranged by the graduate teaching secretary, and contain the small mistakes in his work. Only by stimulating the professional identity of graduate teaching secretaries can they be extraordinary in ordinary posts and enhance their initiative and enthusiasm in their work.

\subsection{Actively Improve Their Own Quality}

Due to the complexity of the work, it is inevitable that graduate teaching secretaries will be criticized by leaders, complained by teachers and dissatisfied by students. It is necessary to maintain a good mentality and psychological endurance, strengthen the study of Ideological and political theory, and actively correct the working attitude. It is necessary to have a strong planning for the work, make a good plan for the routine affairs in advance, pay attention to the collection and accumulation of various information about teaching in the college, and record the work experience and mistakes at any time, so as to accumulate experience for future work. To actively improve their own quality and ability, to fully understand their own value, to understand the nature of their work is to actively serve the tutors and students, the school's principles and policies timely convey to the tutors and students. Graduate teaching secretary and counselors should also do a good job of cooperation, because the two work 
inseparable, to help each other, in order to make the work smoothly.

\section{CONCLUSION}

Here is the summary of this paper: To sum up, this paper discusses the important role of graduate secretary in teaching work, points out the imbalance between the payment and acquisition of teaching secretary in teaching work, and finally puts forward how to improve the enthusiasm and sense of responsibility of teaching secretary in work, which has been verified in practice and is effective.

\section{ACKNOWLEDGMENTS}

The work is supported by teaching research and reform project of postgraduate education of Chengdu University of Information Technology, named "Research on practical ability training of professional degree postgraduates based on tutor group system under the background of new engineering".

\section{REFERENCES}

[1] Sun Songyu, Ke Zhenjie, Gong Jing. Analysis on the work of Teaching Secretary for graduate students in Colleges and Universities under the new situation [J]. Science and technology innovation guide, 2015, 12 (18): 219-220.

[2] Li Xing. Problems and coping strategies of graduate education management in Colleges and universities in the new era [J]. Intelligence, 2018 (35).

[3] Han Guoqiang. Research on the main problems and Countermeasures of graduate education management $[\mathrm{J}]$. Curriculum education research, 2014, (8): 50 - 51.

[4] Wu Xiaoyu. Understanding of the responsibilities and innovative working methods of teaching secretaries in Colleges and departments [J]. Education and teaching forum, 2016, (42): 130-131.

[5] Lin Yan. Analysis on how to improve the management level of University Teaching Secretary [J]. Higher education, 2013 (1): 129. 